\title{
Evaluation of the awareness and practices of farmers on gastric ulceration in pigs in the Oyo State, Nigeria
}

\author{
O. O. Omotosho ${ }^{1, *}$, O. A. Morakinyo ${ }^{2}$, O. O. Adedayo ${ }^{1}$, A. O. Odukaye ${ }^{1}$, B. O. Emikpe ${ }^{3}$
}

${ }^{1}$ Department of Veterinary Medicine, University of Ibadan; ${ }^{2}$ Livestock Improvement Program, Institute of Agricultural Research and Training, Moor Plantation, Ibadan; ${ }^{3}$ Department of Veterinary Pathology, University of Ibadan

\begin{abstract}
Background: Gastric ulceration has been identified as a significant problem affecting pigs worldwide causing economic losses and is of a welfare concern. Limited information was available on the awareness of farmers of gastric ulcers and the exposure of pigs to some identified predisposing factors. This study sought to fill this information gap.

Methods: Data were collected from 148 registered pig farmers in 12 local government areas of Oyo state using structured questionnaires. On-site assessment of farms' facilities and management practices was observed to determine the level of exposure of pigs to known predisposing factors.

Results: Most (84.5\%) of the farmers were males with the majority (89.2\%) being Christians. The scale of production was mostly (71\%) between $50-150$ pigs, while many $(52.7 \%)$ had farming experience of over 5 years. Most $(83.1 \%)$ of the farmers were aware of the occurrence of gastric ulcers in humans while only $23 \%$ were aware that pigs were affected. A high proportion (69\%) of the farmers formulated their feeds based on their discretion while some $(28.4 \%)$ used standard formula. A high proportion $(62.2 \%)$ of farmers were utilizing mixed sized particles while $33.1 \%$ farmers were using finely grounded grains with most farmers (84\%) feeding 1-2 times daily. Only $12.2 \%$ farmers evaluated water quality parameters with some $(9.5 \%)$ sourcing water from streams. Farm design and facilities supported manual processes of feeding (100\%), watering $(60.8 \%)$ and sorting $(85.8 \%)$. Restraints were mostly (96\%) dependent on physical methods.

Conclusion: This study showed that the awareness of gastric ulceration in pigs among farmers in the Oyo state was limited and pigs were consistently exposed to predisposing factors such as fine feed particles, unhygienic water, and stressful handling.
\end{abstract}

Keywords: Awareness, Knowledge, Predispose, Pigs, Ulcers

*Correspondence: oo.omotosho@gmail.com

All right reserved 0451/2019

Copyright (C) 2019 Bangladesh Society for Veterinary Medicine. This is an open access article under the CC BY license (http://creativecommons.org/licenses/by/4.0/), which permits unrestricted use, distribution, and reproduction in any medium, provided the original author and source are credited. 


\section{Introduction}

Gastric ulcers affect pigs of all ages leading to significant economic losses. It is also a welfare concern as it causes excruciating pains (Ayles $e t$ al., 1996; Friendship, 2003). The condition has been documented for over 70 years in pigs (Monteiro, 2011) and it appears to have increased in frequency of occurrence with the introduction of confinement rearing and the use of grain-based processed rations in the diet of pigs (Friendship, 1999). The prevalence varies greatly from herdto-herd and it is known to cause anorexia, acute gastric hemorrhage, chronic anemia, reduced weight gain and sudden death (Ayles et al., 1999; Elbers et al., 1995). The pig stomach is monogastric and its mucosa is divided anatomically into the non-glandular (pars oesophagea) and the glandular (cardia, fundus and antrum) regions. Slaughter house surveys over many years from different regions of the world have revealed a high prevalence of gastric ulcers often restricted to the pars oesophagea with its frequency of occurrence being as high as $100 \%$ in some herds (Christensen and Cullinane, 1990; Elbers et al., 1995; Straw et al., 1992). Gastric lesions occur at a lower rate in the glandular regions (Monteiro, 2011). Ulcers of the pars oesophagea usually involve only the submucosa, but they may advance to the muscularis externa and occasionally the serosa (Barker et al., 1993).

Gastric ulceration in swine is generally believed to have several predisposing factors which include age, breed, sex, heredity, infection and parasitism, toxicity, trauma, nutrition and management factors (Friendship, 1999). There are increasing number of studies especially within the last 20 years on the role of infectious agents in the formation of gastric ulcers with Helicobacter species being of prime interest (Roosendaal et al., 2000; Choi et al., 2001; Krakowka and Ellis, 2006; Appino et al., 2006).

There are increasing numbers of studies documenting the occurrence and predisposing factors of gastric lesions in pigs in Nigeria (Majekodunmi et al., 2013; Omotosho et al., 2015). For the control of the condition, it is necessary to assess the level of awareness of farmers and the level of exposure of pigs to gastric ulceration for improved production efficiency and better welfare of the pigs.

\section{Materials and Methods \\ Definition of terms}

Awareness refers to knowledge possessed by the farmers and practices refer to routine procedures adopted by the farmers for managing pigs.

\section{Study location}

Oyo state is one of the major pig producing states in Nigeria. It is one of the 36 states in Nigeria, ranked 14th by size and it covers an area of approximately 28,454 square kilometers. There are 33 local government areas in the state with 11 of them being within the capital city, Ibadan. The climate is equatorial, notably with dry and wet seasons with relatively high humidity. Agriculture is the main occupation of the people of Oyo State (NPC, 2017). The study was carried out between March and August 2018 among 148 pig farmers in 12 selected local government areas in Oyo state (Table 1).

Table 1. Distribution of the surveyed pig farmers in Oyo state

\begin{tabular}{|c|c|c|}
\hline S/No & $\begin{array}{l}\text { Local } \\
\text { Government Area }\end{array}$ & $\begin{array}{c}\text { Number of } \\
\text { farmers/farms }\end{array}$ \\
\hline $\mathbf{1}$ & Egbeda & 26 \\
\hline 2 & Lagelu & 14 \\
\hline 3 & Akinyele & 17 \\
\hline 4 & Iddo & 23 \\
\hline 5 & Oluyole & 9 \\
\hline 6 & Ona-ara & 6 \\
\hline 7 & Oyo-East & 11 \\
\hline 8 & Oyo-West & 9 \\
\hline 9 & Ibarapa-East & 6 \\
\hline 10 & Ogbomoso-North & 13 \\
\hline 11 & Ogbomoso-South & 8 \\
\hline \multirow[t]{2}{*}{12} & Surulere & 6 \\
\hline & Total & 148 \\
\hline
\end{tabular}

\section{Samples selection}

Cross sectional survey of 148 farmers registered with the pig farmers' association of Nigeria, Oyo state (PFAN) across 12 selected local governments was done. All participants were of age between 28 and 72 years. Structured 


\section{Gastric ulceration in pigs}

questionnaires were administered to the farmers in a face-to-face interview approach. Consent was obtained from the participants after the purpose of the study was described and the questions were interpreted to local languages, when needed, to improve accuracy of data obtained.

On-site assessment of farms' facilities and farmers' practices

On-site assessment of farms' facilities and farmers' practices was done on the 148 farms. This included assessment of feed quality, feeding routine, water source, restraint practices and housing facilities.

\section{Results}

Most $(84.5 \%)$ of the farmers were males with majority (89.2\%) being Christians. The scale of production was mostly (71\%) between $50-150$ pigs, while many $(52.7 \%)$ had farming experience of over 5 years (Table 2). Most (83.1\%) of the farmers were aware of the occurrence of gastric ulcers in humans while only $23 \%$ were aware that pigs are affected (Figure 1). A high proportion $(69 \%)$ of the farmers formulated their feeds based on their discretion while some $(28.4 \%)$ used standard formula (Figure 2). $33.1 \%$ used finely grounded grains while $62.2 \%$ utilised mixed particle sizes (Figure 3) with most farmers (84\%) feeding 1-2 times daily (Figure 4). Only 12.2\% evaluated water quality parameters with some $(9.5 \%)$ sourcing water from streams (Figure 5). Farm design and facilities mostly supported manual processes of feeding (100\%), watering $(60.8 \%)$ and sorting $(85.8 \%)$ (Figure 6). Restraint was mostly (96\%) dependent on physical handling methods.

Table 2. Information on the pig farmers interviewed in Oyo state

\begin{tabular}{llll}
\hline & & Number (148) & Percentage (\%) \\
\hline Sex & Male & 125 & 84.5 \\
Religion & Female & 23 & 15.5 \\
& Christianity & 132 & 89.1 \\
& Islam & 14 & 9.5 \\
& Others & 2 & 1.4 \\
Scale of production & $0-49$ & & \\
& $50-99$ & 4 & 2.7 \\
& $100-149$ & 37 & 25 \\
& $150-199$ & 68 & 46 \\
& $200-$ Above & 18 & 14.2 \\
& & & 12.2 \\
Farmer's experience & $0-4$ & 32 & 21.6 \\
& $5-9$ & 38 & 25.7 \\
& $10-14$ & 47 & 31.8 \\
& $15-$ Above & 31 & 21 \\
\hline
\end{tabular}




\section{Omotosho and others}

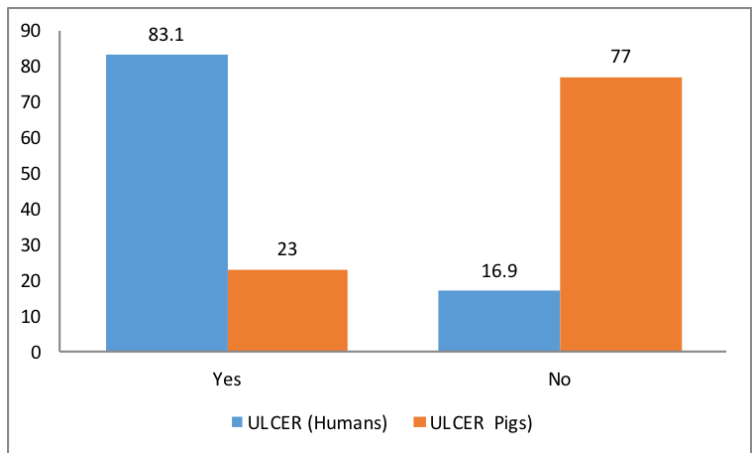

Figure 1: Awareness of pig farmers on the occurrence of gastric ulceration in humans and pigs

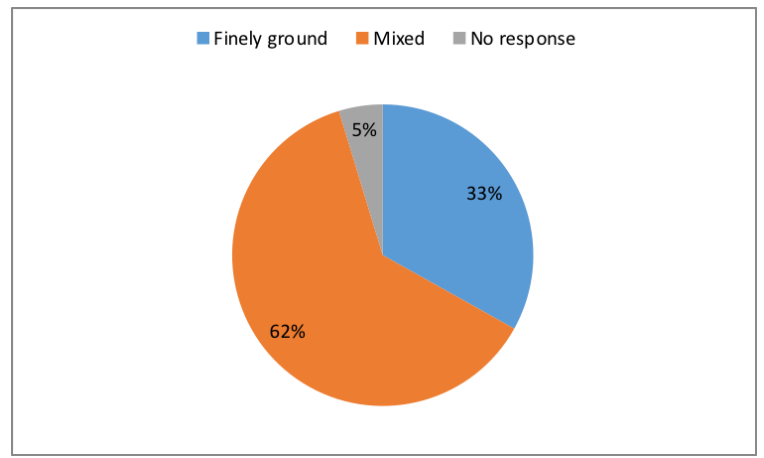

Figure 3: Particle size of feed utilised by pig farmers in Oyo state

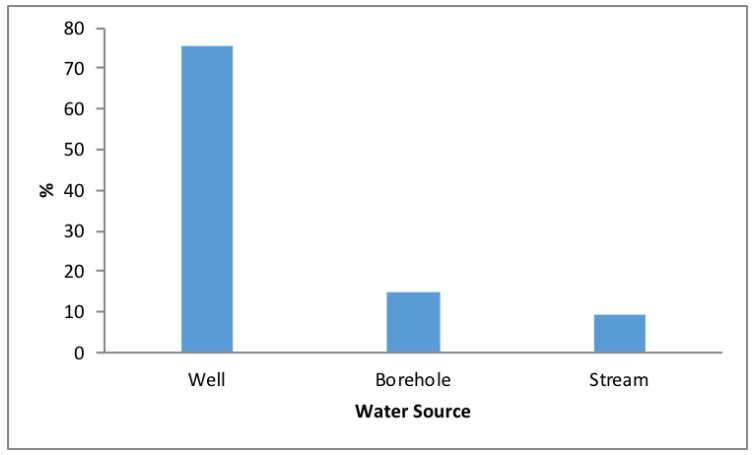

Figure 5: Water sources used by pig farmers in Oyo state

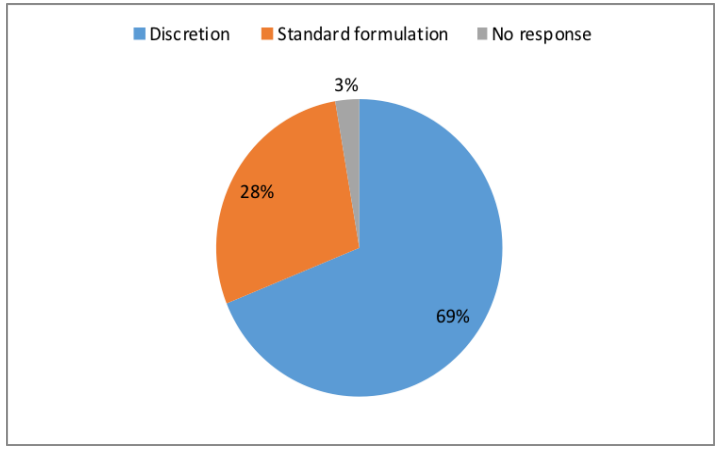

Figure 2: Farmer's practices on pig feed formulation in Oyo state

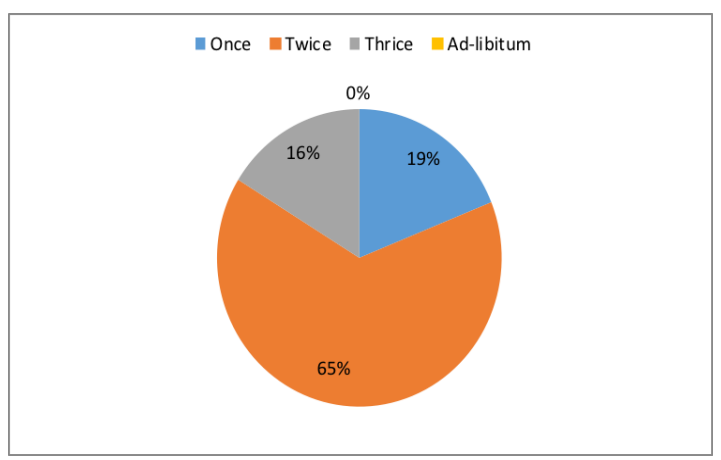

Figure 4: Frequency of feeding of pigs by farmers in Oyo state

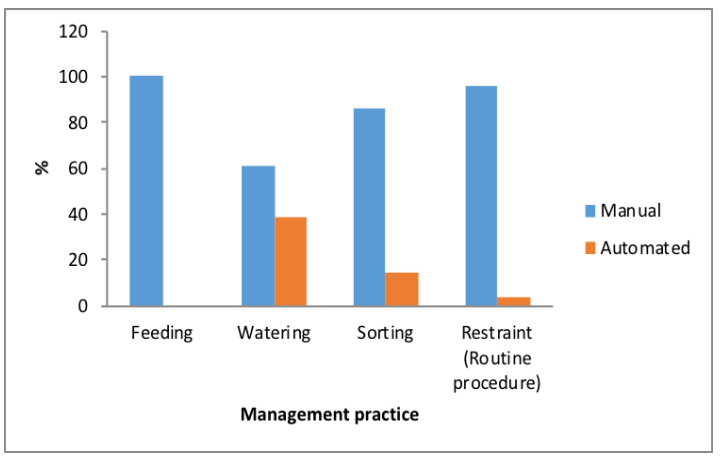

Figure 6: Methods adopted by pig farmers for performing management practices in Oyo state. 


\section{Discussion}

This study clearly revealed that farmers had limited information on the occurrence and predisposing factors of gastric ulceration in pigs in Nigeria despite their relative awareness of this condition in humans. The male dominance observed in the industry is in line with previous finding (Abiola et al., 2015). This may be due to the present laborious management practices adopted which largely depended on the use of physical force in controlling pigs. Despite the fact that many of the farmers have advanced years of practice, their scale of production was still at subsistence level, such scale of production is marginally profitable and will contribute minimally to the country's economy. This situation may be due to economic reasons as previously documented (Oni and Yusuf, 1999) or the influence of diseases. There is urgent need to investigate and proffer lasting solution to factors that may be responsible for the widespread limited scale of pig production. A high percentage of the farmers based on their personal experience or that of acquaintances were aware of the occurrence of ulcers in humans but only few neither knew that pigs are also affected nor the factors that may predispose pigs to the condition. This low level of awareness among relatively experienced farmers shows that the condition had received minimal attention over the years despite being a significant ongoing problem in pigs in Nigeria (Omotosho et al., 2016).

Several studies have investigated the relationship between gastric ulceration in pigs and nutritional factors such as feed particle size, quality and processing of ingredients, nutritional balance and frequency of feeding (Robertson et al., 2002; Amory et al., 2006). Less than one third of the farmers in this present study use scientifically developed feed formulation with the larger percentage depending on their discretion for compounding feeds for pigs. Such practice predisposes pigs to deficiency or toxicity of micronutrients and trace elements which are essential for the integrity and function of organs including the stomach.
Some of the farmers have preference for fine particle sized grains in producing pig feeds. Although fine particle sized grains have increased surface area for enzyme action, mixes uniformly with protein, vitamin and mineral supplements and improves the efficiency of digestion leading to better body weight gains in pigs (Monteiro, 2011), it is known to increase significantly the incidence of gastric ulceration in pigs. Lawrence et al. (1998), Wondra et al.(1995), Eisemann and Argenzio (1999) and Amory et al. (2006) among other workers found that finely ground diets even if pelletized are associated with increased incidence of gastric ulcers compared to what was observed when pigs were fed with coarsely ground diets. This may partly be due to the rapid stomach emptying when pigs are fed rations with fine particle size (Lang et al., 1998) and it is known that any factor that causes an empty stomach is a risk factor for gastric ulceration. The timing and frequency of feeding of pigs is also known to affect the occurrence of gastric ulcers. Most farmers practiced feed restriction, feeding their pigs only once or twice a day. The restriction of feed observed in this study may be a strategy aimed at reducing the cost of production. Feed restriction is a known stress factor which has been associated with higher frequency of gastric ulcers in pigs (Robert et al., 1991). Periodic assessment of water quality is very important in livestock production to prevent waterborne infections. Water quality assessment was not a frequent practice among pig farmers in Oyo state as few had water quality assessment report. Evaluation of the $\mathrm{pH}$ of the water supplied to pigs is important as this estimates the buffering effect of the water which may alleviate the occurrence of gastric ulcers (Monteiro, 2011). Robertson et al. (2002) found an association between water source and gastric ulceration in pigs. They suggested that bacterial and algal blooms in surface water sources during hot weather and the microbiological quality of the water may have influence in the occurrence of oesophago-gastric ulcer in pigs. In humans, surface water sources contaminated with Helicobacter species from feces has been suggested to increase the incidence of gastric ulcers. (Choi et al., 2001). Further studies should 
be conducted to assess the physicochemical and microbiological status of water used in pig farms to determine their role in gastric ulceration and other diseases.

Most of the routine pig management practices observed on the farms were manual. The farm designs and facilities mostly supported manual processes of feeding, watering and sorting. This made the management processes labor intensive with the frequent physical handling of pigs predisposing them to stress. Stress is well recognized as a predisposing factor of gastric lesions in pigs (Salim, 1990, Swaby and Gregory, 2012). Stressors that have been identified to adversely affect the health of pigs include forced immobilisation, social stress from mixing, rearing in confinement, high stocking densities, stressful transport conditions, transfer to an unfamiliar environment and concurrent diseases (Ramis et al., 2005; Amory et al., 2006).

\section{Conclusions}

The level of awareness of farmers in Oyo state, Nigeria on the occurrence and predisposing factors of gastric ulcers in pigs was low. This situation is largely responsible for the adoption of management practices that constantly expose pigs to risk factors for gastric ulceration. It is therefore important that urgent steps are taken to educate pig farmers on this condition in order to improve the production output and the welfare status of pigs in Oyo state, Nigeria.

\section{Acknowledgement}

The authors appreciate the executives and members of the pig farmers' association of Nigeria (PFAN), Oyo state branch for their cooperation during the study.

\section{Funding}

The authors funded the project.

\section{Competing Interest}

The authors declare that there are no competing interests.

\section{References}

1. Abiola JO, Omotosho OO, Adeniyi OM and Ayoade GO. Sociodemographic characteristics of swine producers and swine management practices in Ibadan, Oyo State, Nigeria. Alexandria Journal of Veterinary Sciences. 2015; 47: 7-17.

2. Amory JR, Mackenzie AM and Pearce GP. Factors in the housing environment of finisher pigs associated with the development of gastric ulcers. Veterinary Record. 2006; 158: 260-264.

3. Appino S, Guarda F, Pregel P, Amedeo S, Cutufia M A, Bellonio G, Ponzetto. Detection of Helicobacter candidatussuisby PCR in oesophagogastric ulcers of swine in Italy. Acta Veterinaria Hungarica. 2006; 54: 517-524.

4. Ayles HL, Friendship RM, Ball RO. Effect of dietary particle size on gastric ulcers, assessed by endoscopic examination, and relationship between ulcer severity and growth performance of individually fed pigs. Swine Health and Production. 1996; 4: 5.

5. Ayles HL, Friendship RM, Bubenik GA and Ball RO. Effect of feed particle size and dietary melatonin supplementation on gastric ulcers in swine. Canadian Journal of Animal Science. 1999; 79:179-185.

6. Barker IK, Van Dreumel AA and Palmer N. Pathology of Domestic Animals, Vol. 2, 4th ed. London: Academic Press, 1993; p. 32, 65-72.

7. Choi YK, Han JH and Joo HS. Identification of novel Helicobacter species in pig stomachs by PCR and partial sequencing. Journal of Clinical Microbiology. 2001; 39: 3311- 3315.

8. Christensen $\mathrm{N}$ and Cullinane L. Monitoring the health of New Zealand abattoirs. New Zealand Veterinary Journal. 1990; 38: 136141.

9. Eisemann JH and Argenzio RA. Effects of diet and housing density on growth and stomach morphology in pigs. Journal of Animal Science. 1999; 77: 2709-2714.

10. Elbers AR, Hessing MJ, Tielen MJ and Vos $\mathrm{JH}$. Growth and oesophagogastric lesions in finishing pigs offered pelleted feed ad libitum. Veterinary Records. 1995; 136: 588590.

11. Friendship RM. Gastric Ulcers. In: Diseases of Swine. Straw, B.E., D'allaire, S., 
Mengeling, L., Taylor, D.J. Eds. Iowa State University Press, Ames IA. 1999; 685-694.

12. Friendship RM. Gastric Ulcers: An underrecognized cause of mortality and morbidity.Advances in Pork Production. 2003;14: 159.

13. Krakowka S and Ellis J. Reproduction of severe gastroesophageal ulcers (GEU) in gnotobiotic swine infected with porcine Helicobacter pylori-like bacteria. Veterinary Pathology. 2006; 43: 956-962.

14. Lang J, Blikslager A, Regina D, Eisemann J and Argenzio R. Synergistic effect of hydrochloric acid and bile acids on the pars esophageal mucosa of the porcine stomach. American Journal of Veterinary Research. 1998; 59: 1170-1176.

15. Lawrence BV, Anderson DB, Adeola O, Cline TR (1998) Changes in pars esophageal tissue appearance of the porcine stomach in response to transportation, feed deprivation, and diet composition. Journal of Animal Science. 1998; 76: 788-795.

16. Majekodunmi MM, Omotosho OO, Emikpe BO and Olufemi BE. The incidence of gastric lesions in slaughtered pigs in Ibadan, Nigeria. Sokoto Journal of Veterinary Sciences. 2013; 11(1): 22-27.

17. Monteiro, SDAPS. Prevalence and risk factors for gastric ulcers in swine, http://repositorio-

aberto.up.pt/handle/10216/22219. Accessed on 15 October, 2018.

18. NPC: "2006 PHC Priority Tables NATIONAL POPULATION COMMISSION". population.gov.ng.2017. Retrieved 2018-0730.

19. Omotosho OO, Ayoade GO, Emikpe BO, Adediran OA and Uwalaka EC. Identification of predisposing and risk factors associated with gastric lesions in pigs. Asian Pacific Journal of Tropical Diseases.2015; 5(10): 930-934

20. Omotosho OO, Emikpe BO, Lasisi OT and Jarikre TA. Prevalence, distribution and pattern of gastric lesions in slaughtered pigs in south-western Nigeria. Onderstepoort Journal of Veterinary Research. 2016; 83(1):1063.

21. Oni OA and Yusuf SA. The effects of farmers' socio-economic characteristics on livestock production in Ibadan metropolis. In: Proceeding of the 4th Conference of the Animal Science Association of Nigeria. IITA, Ibadan. 1999; p. 245-248

22. Robert S, Matte JJ Girard CL. Effect of feeding regimen on behaviour of growingfinishing pigs supplemented or not supplemented with folic acid. Journal of Animal Science; 1991; 69: 4428-4436.

23. Robertson, ID, Accioly JM, Moore KM, Driesen SJ, Pethick, DW, Hampson, DJ. Risk factors for gastric ulcers in Australian pigs at slaughter. Preventive Veterinary Medicine. 2002; 53: 293-303.

24. Roosendaal R, Vos JH, Roumen T, van Vugt R., Cattoli G, Bart A., Klaasen, HL, Kuipers, EJ, Vandenbroucke-Grauls, CM, Kusters, JG. Slaughter pigs are commonly infected by closely related but distinct gastric ulcerative lesion-inducing gastrospirilla. Journal of Clinical Microbiology. 2000; 38: 2661-2664.

25. Salim AW. Acute Gastric Mucosal Injuries - Origin of the Stress-Induced Injury? a Review. The Journal of the Royal MedicoChirurgical Society of Glasgow, and the Scottish Society of Experimental Medicine. 1990; 35:1.

26. Straw B, Henry S, Nielsen J, Doster A, Moxley R, Webb D., Hogg, A. 'Prevalence of lesions in the pars esophagea of normal and sick pigs', in Proceedings of the 12th International Pig Veterinary Society Congress, The Hague, Netherlands. August 17-20, 1992; p 12:386.

27. Swaby H, Gregory, NG. A note on the frequency of gastric ulcers detected during post-mortem examination at a pig abattoir. Meat Science. 2012; 90: 269-271. 